اثر ضدافسردگى عصاره آبى دارجين (Cinnamomum zeylanicum L.) در مدل شناى اجبارى در موش كوجى آزمايشخاهى

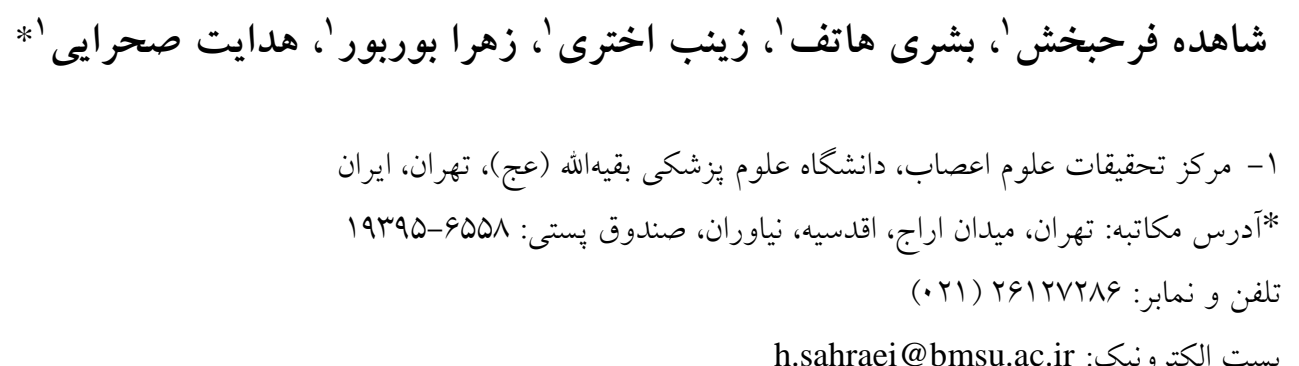

doi: 10.29252/jmp.2.70.154 qV/4/T تاريخ تصويب

تاريخ دريافت:

مقدمه: مطالعات اندكى در مورد اثربخشى عصاره آبى دارجين (CWE) در بيمارىهاى عصبى انجام شده است. در مطالعات قبلى

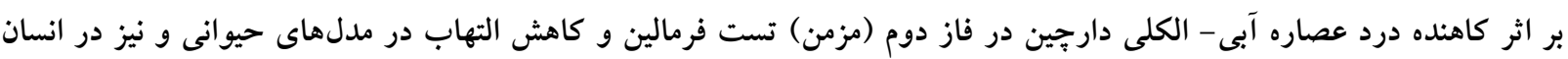

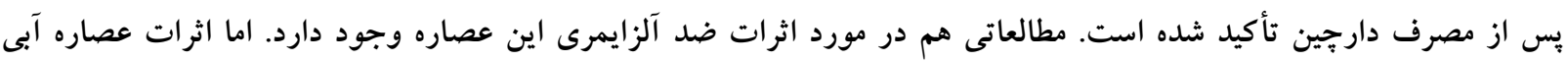
اين گياه در بروز بيمارىهاى مرتبط با دستخاه عصبى بخصوص بيمارى افسردگى مورد بررسى قرار نخرفته است.

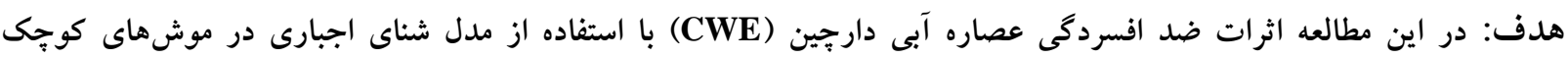
آزمايشگاهى نر بررسى شد.

روش بررسى: CWE با روش جوشاندن از يودر دارجين به دست آمد. موشهاى سفيد آزمايشعاهى نر نزاد

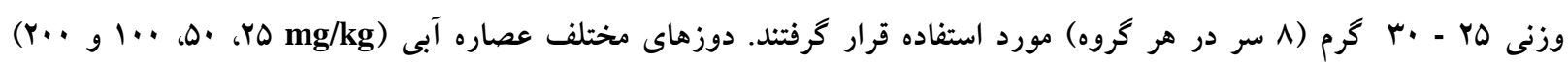

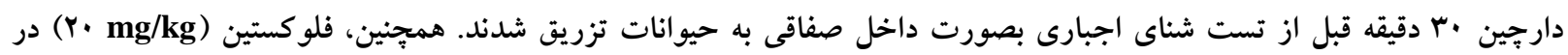

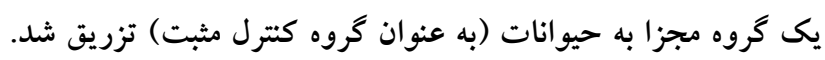

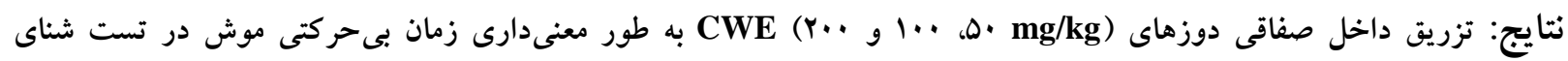

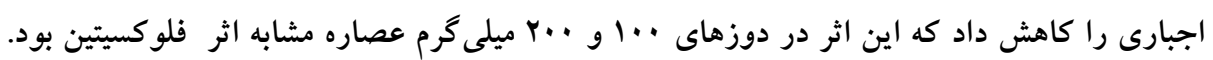

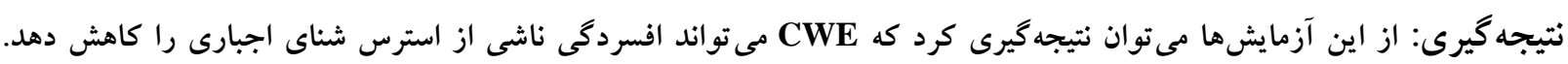
به دليل ناشناخته بودن تركيبات اين نوع از عصاره، مشخص نيست كه مكانيسم اثر اين عصاره در كاهش افسردگى در اين مدل حيوانى جيست. كلوازگگان: افسردگى، تست شناى اجبارى، عصاره آبى دارجين (CWE) 


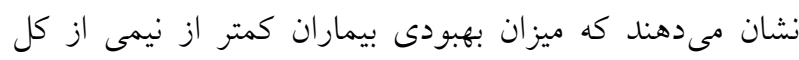

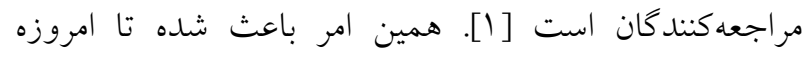
تحقيق در مورد داروهاى كياهى كه بر افسردگى مؤثر هستند

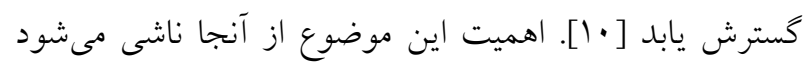

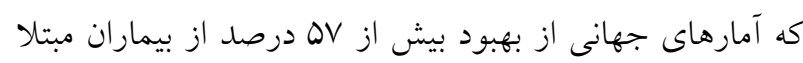

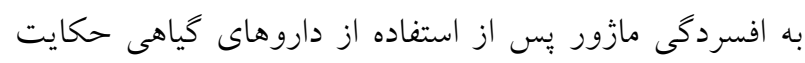

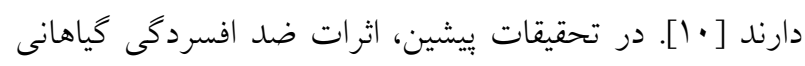

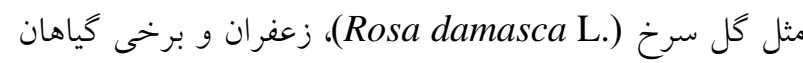

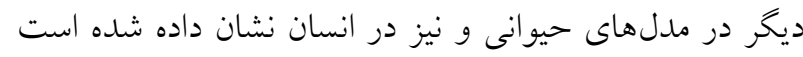

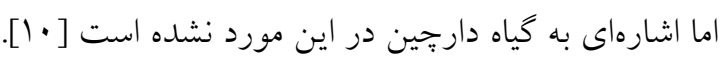

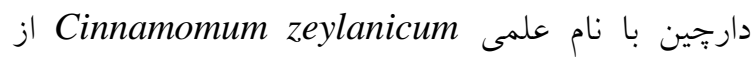

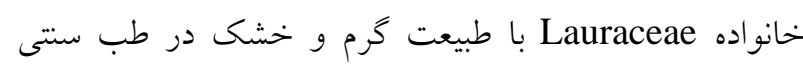

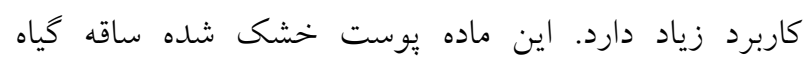
Cinnamomum zeylanicum همجيون جنوب هند و سريلانكا رويش داشته و بومى ايران

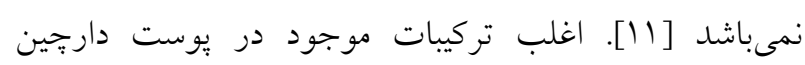

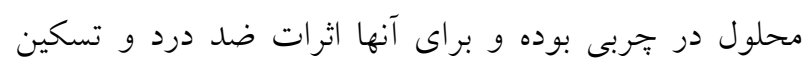

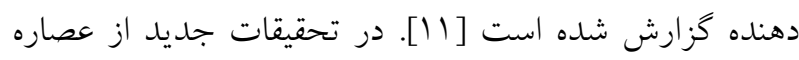

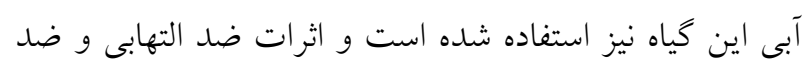

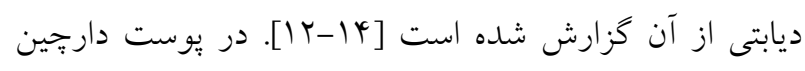

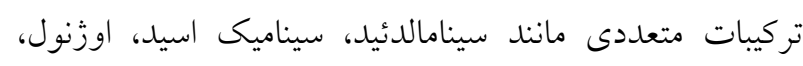

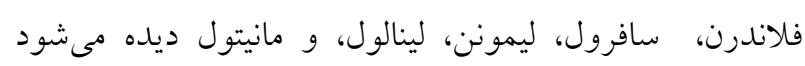

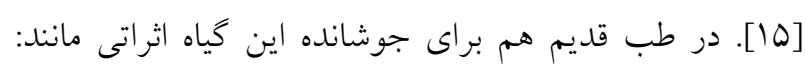

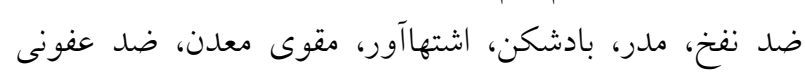

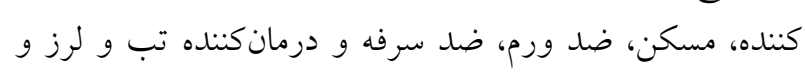

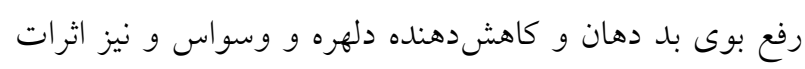

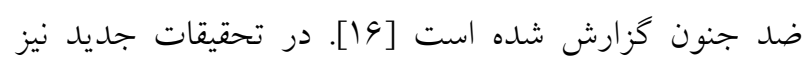

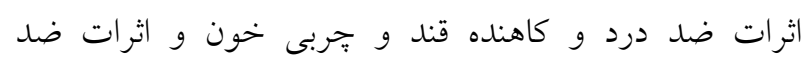

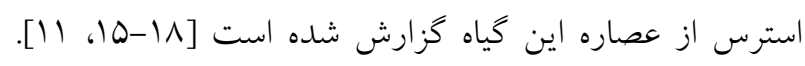

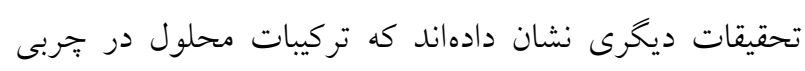

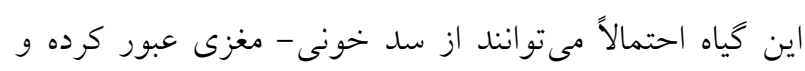

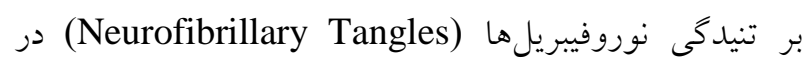
داخل و خارج سلول كه در بيمارى آلزايمر ديده مى نوروند، اثر
كزارشهاى سازمان بهداشت جهانى بيمارى افسردگى را

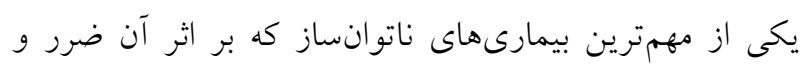

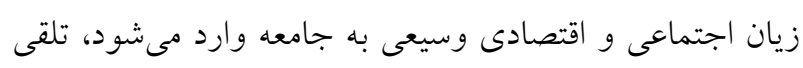

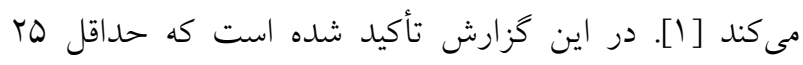

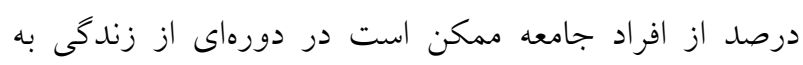

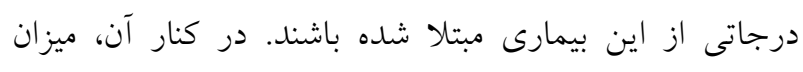

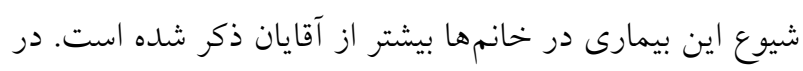

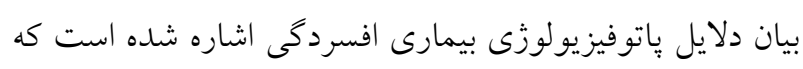

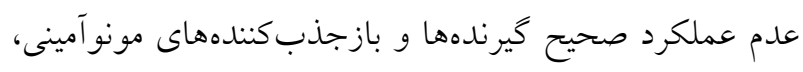

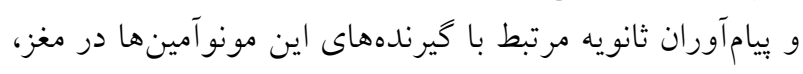

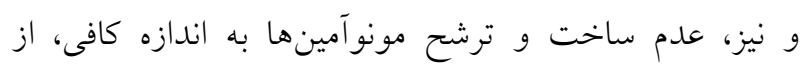

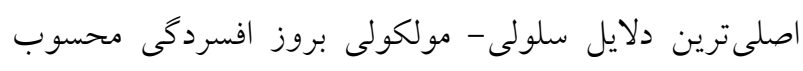

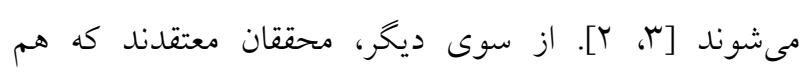

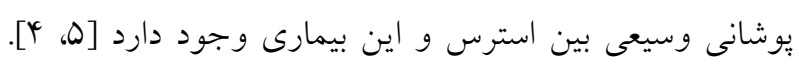

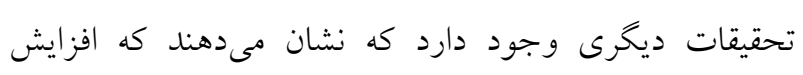

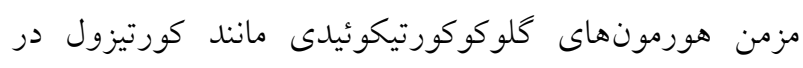

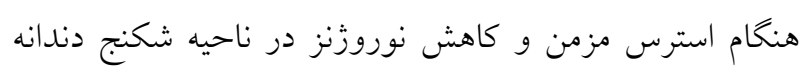

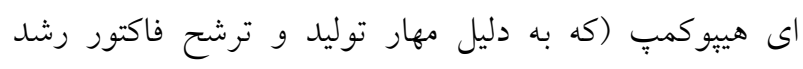

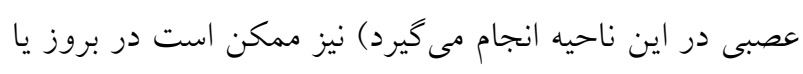

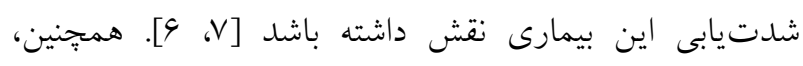

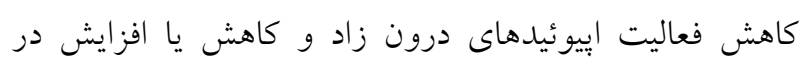

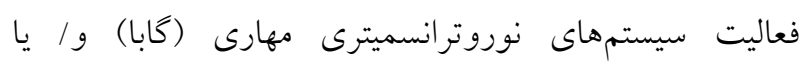

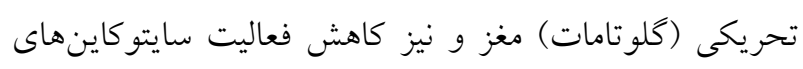

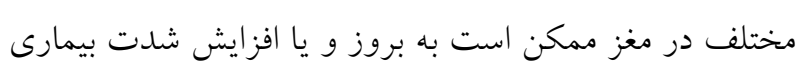
كمى كند [9، ^]. داروهايى كه امروزه براى درمان و يا كتترل

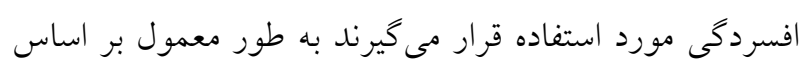

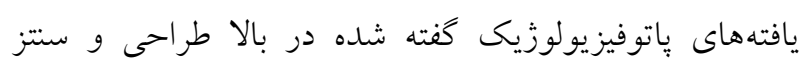

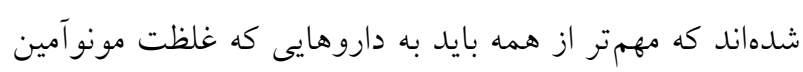

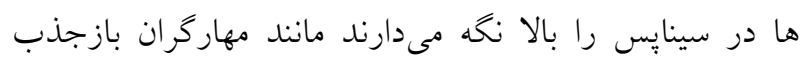

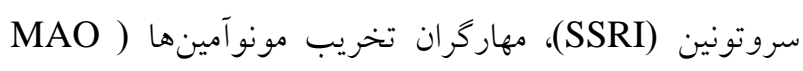
(inhibitors

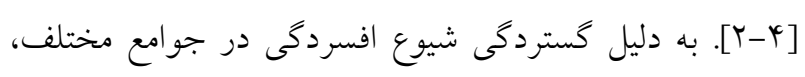

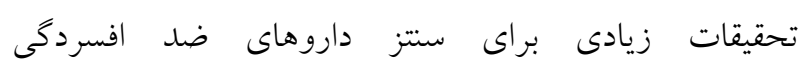


كرم يودر گياه بود (ه/ • درصد). اين عصاره در سالين حل

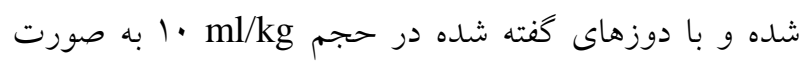

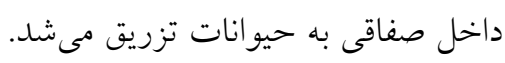

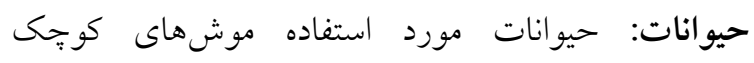

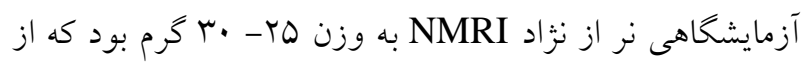

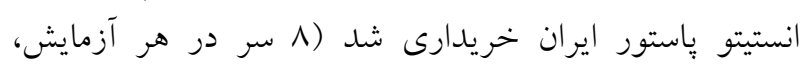

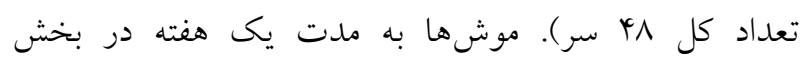

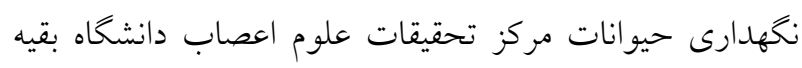

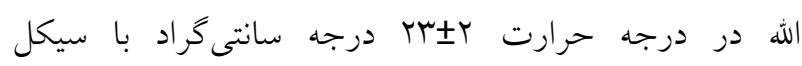

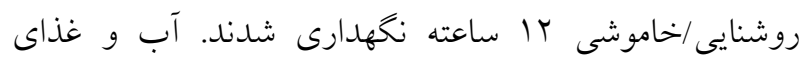

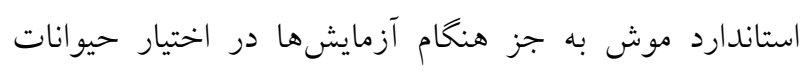

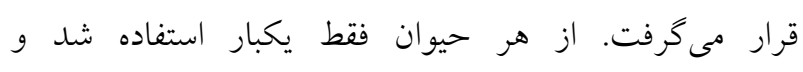

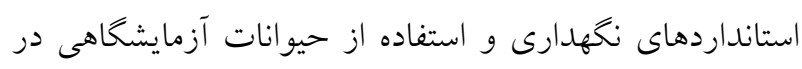
مورد اين حيوانات رعايت شد.

آزمون شناى اجبارى: براى انجام آزمايش، ظرف شيشهاى

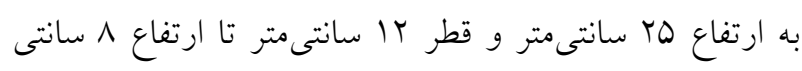

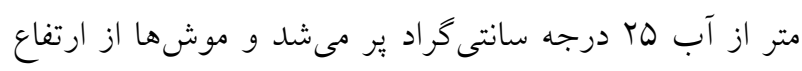

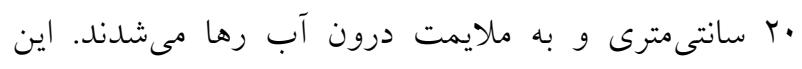

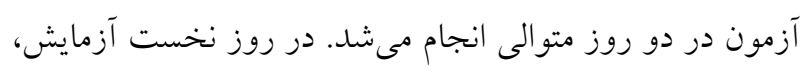

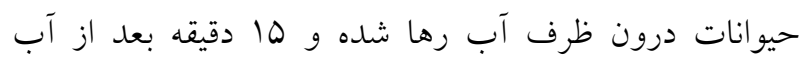

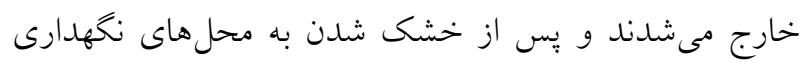

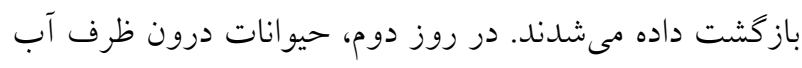

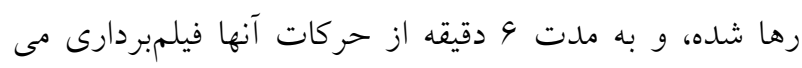

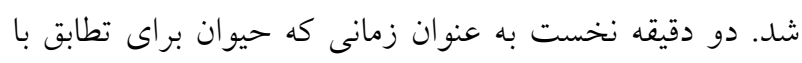

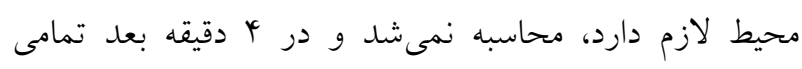

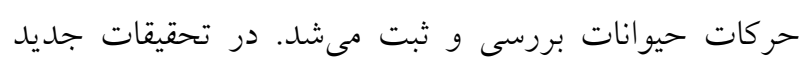

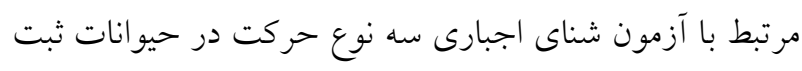

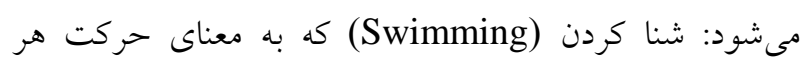

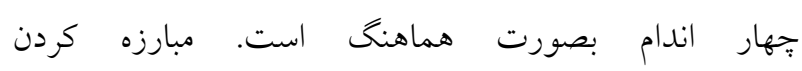
كه به معناى حركت دو اندام جلويى و يا عقبى (Struggling)

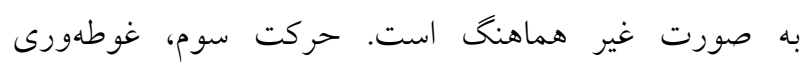
(Floating) يا عقبى است. ثبت زمان هر كدام از اين حركات بايستى بطور
كنند. نتايج اين مطالعات بيان مى كنند كه تزريق عصاره و يا

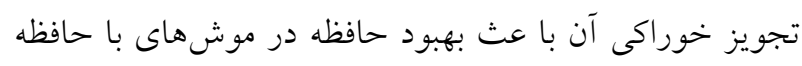

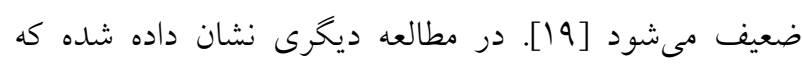
تجويز خوراكى عصاره دارجين باعث بهبود حافظه و از مهار

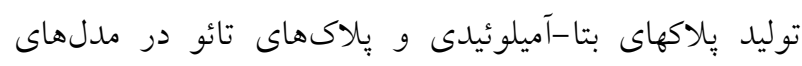

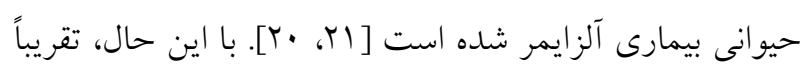

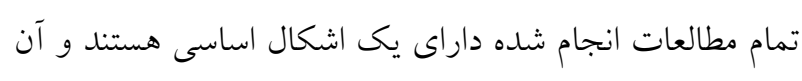

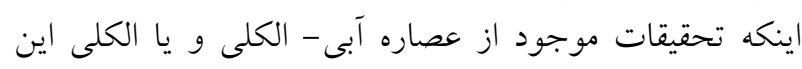

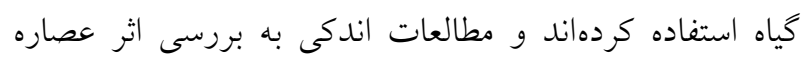

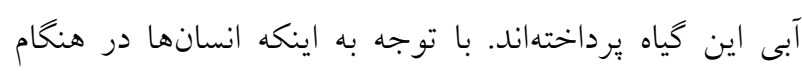

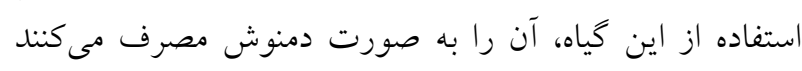

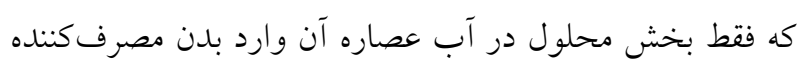

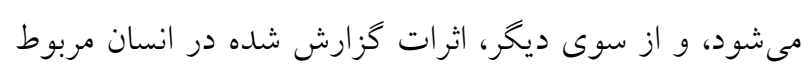

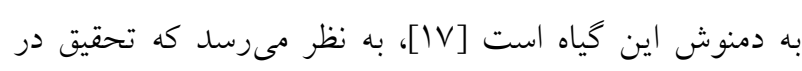

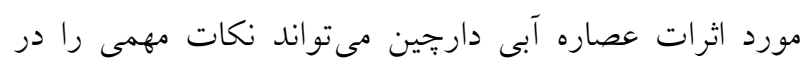

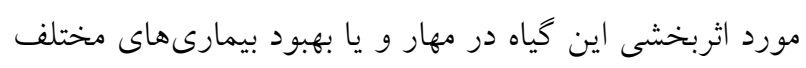

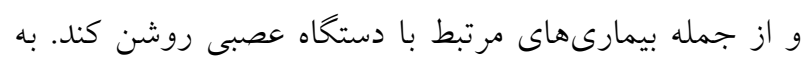

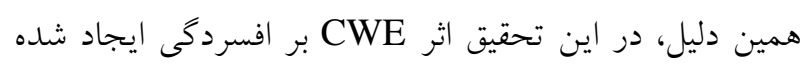

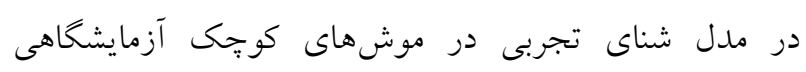
بررسى شد.

\section{مواد و روشها - ماد}

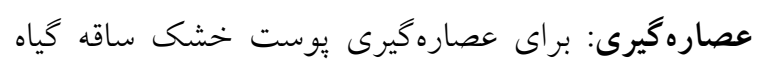

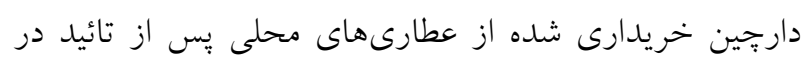

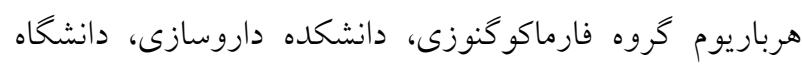

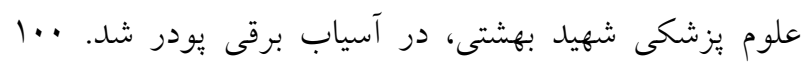

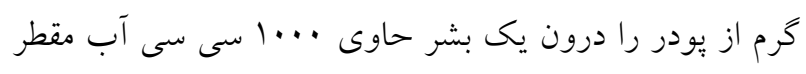

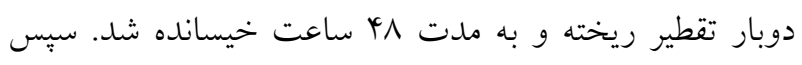

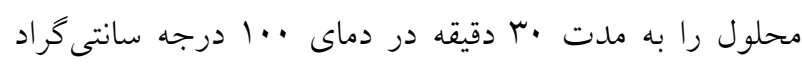

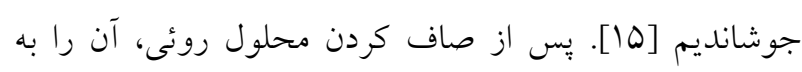

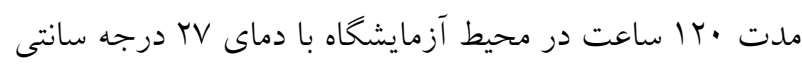

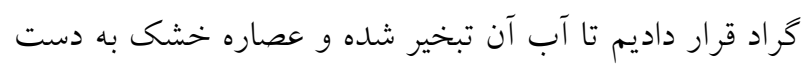

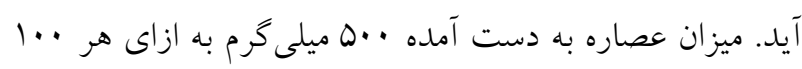




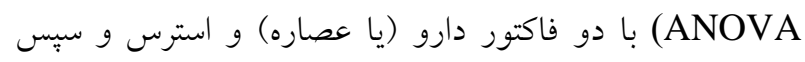

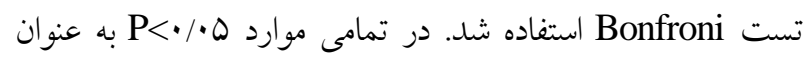

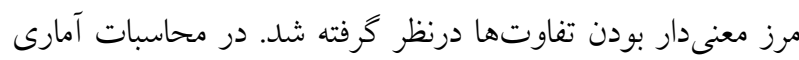
از نرمافزار SPSS ويرايش 19 استفاده شد.

\section{نتايج}

- اثر CWE بر افسردگى ناشى از استرس شناى اجبارى

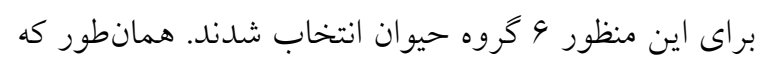

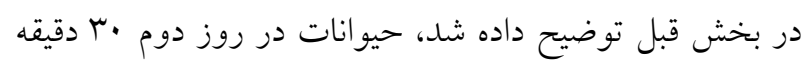

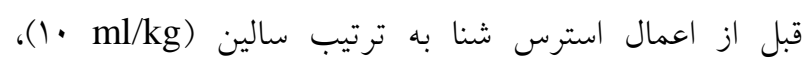

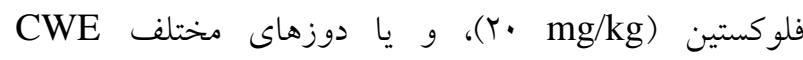

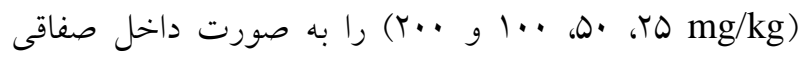

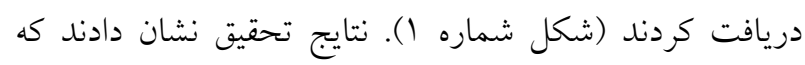

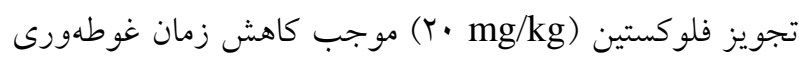

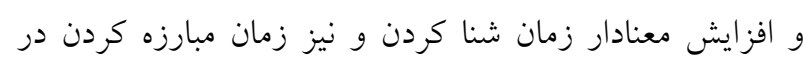

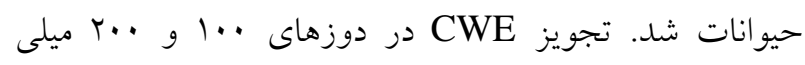

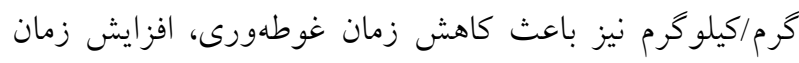

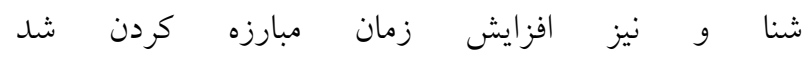
0.

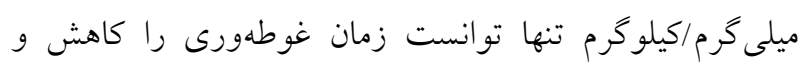

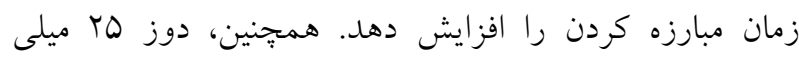

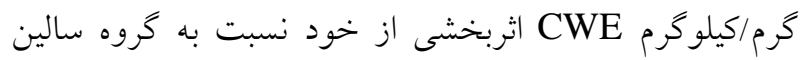
نشان نداد (شكل شماره ()).
جداكانه انجام شود (فيلم مربوط به هر حيوان براى بررسى

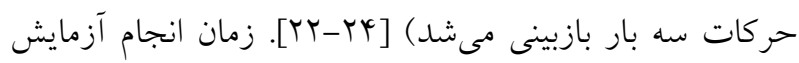

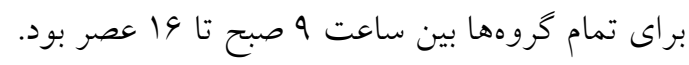

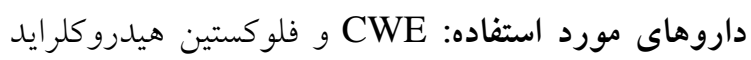

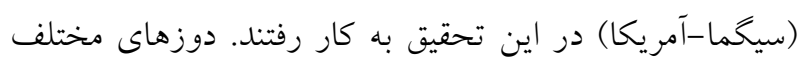

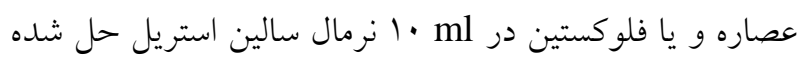

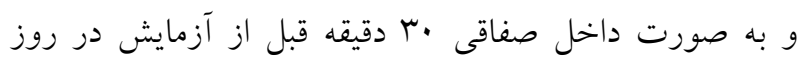

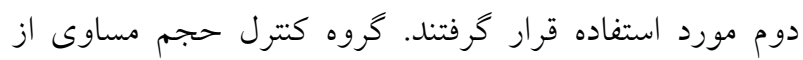
سالين را به صورت داخل صفاقى دريافت كردند.

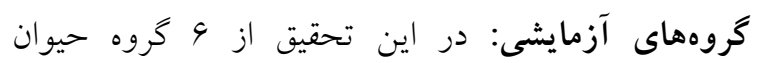

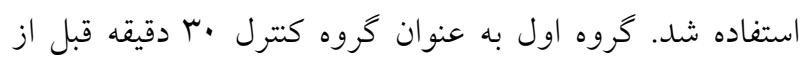

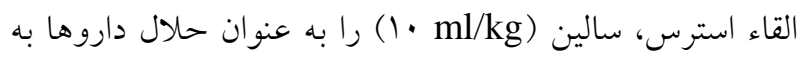

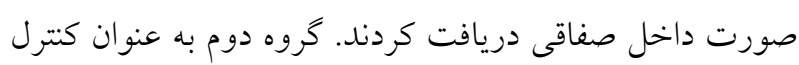
دارويى، •r دقيقه قبل از القاء استرس، فلوكستين (r.mg/kg)

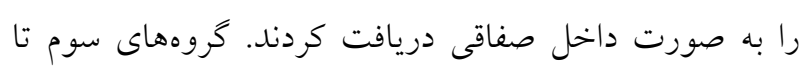

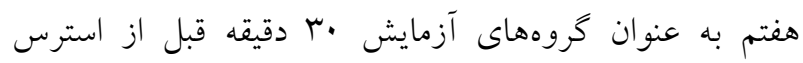
دوزهاى مختلف CWE صورت داخل صفاقى دريافت كردند. دوز فلو كستين با استفاده

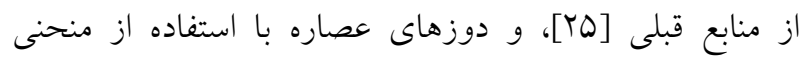
دوز - ياسخ انتخاب شدند. تجزيه و تحليل آمارى: نتايج به صورت ماندان مانغين

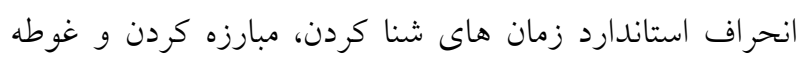

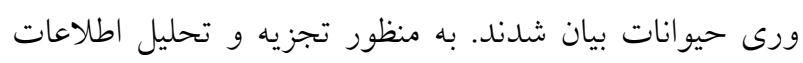
از آزمون آناليز واريانس مرورى ( Repeated Measurement 
فرحبخش و همكاران

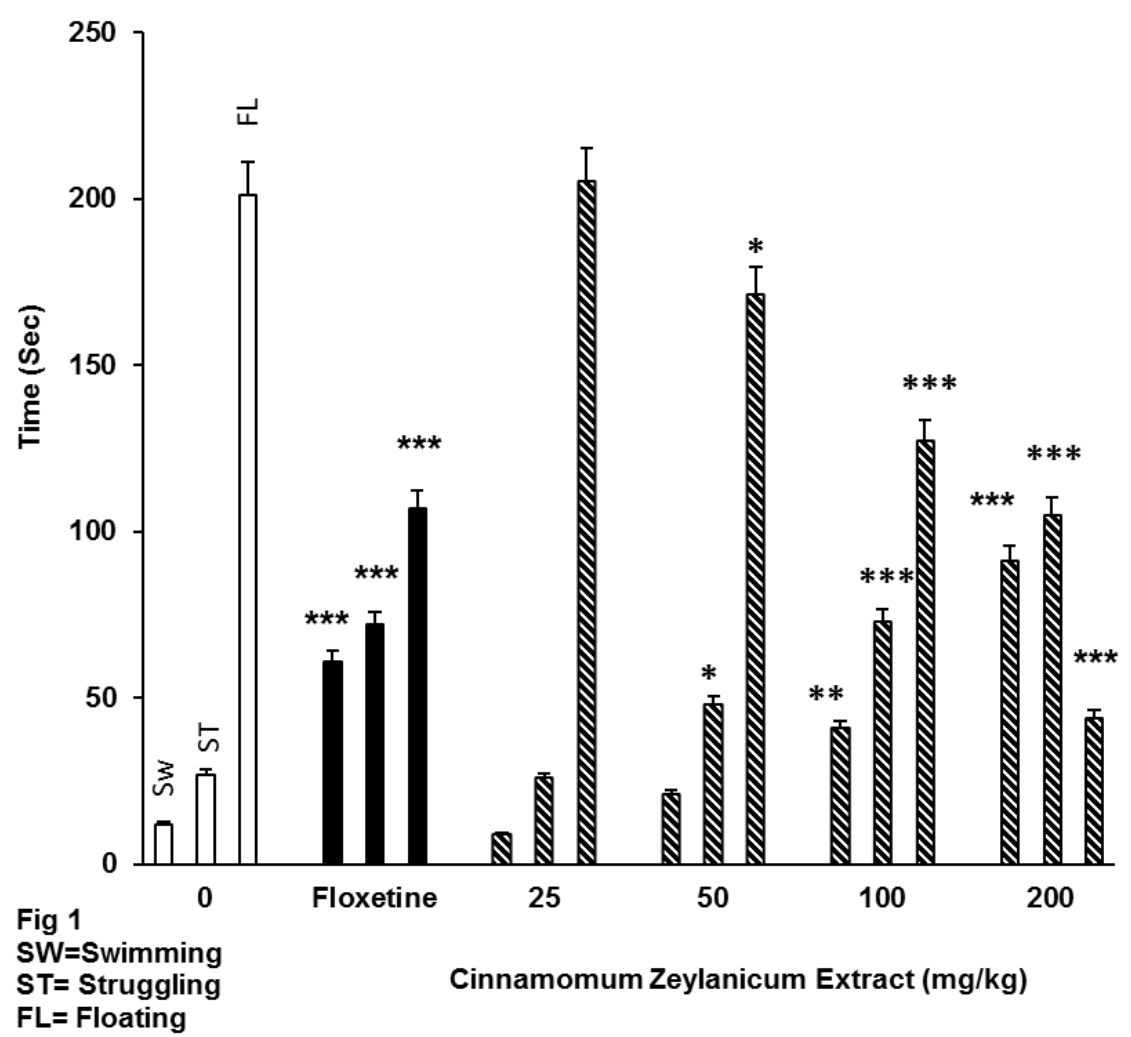

شكل شماره ا- تأثير تجويز داخل صفاقى CWE بر كاهش زمان غوطهورى و افزايش زمان شنا كردن و زمان مبارزه كردن در حيوانات (اين سه زمان

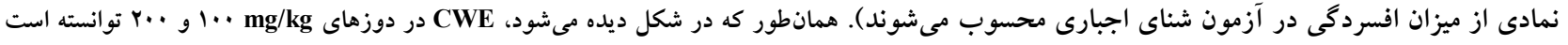

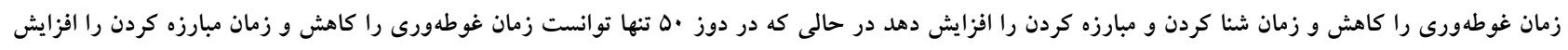

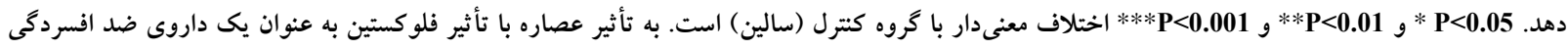
استاندارد دقت كنيد.

اعتقاد بر اين است كه كاهش عملكرد نورونهاى رهاكننده

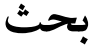
نوروترانسميترهايى نظير سروتونين، نورايى نفرين و دويامين، در اين مطالعه اثر تجويز داخل صفاقى CWE

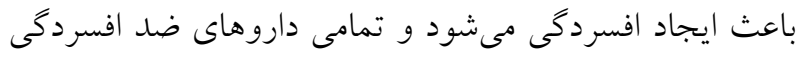
بر كاهش افسردگى (Cinnamomum zeylanicum L.)

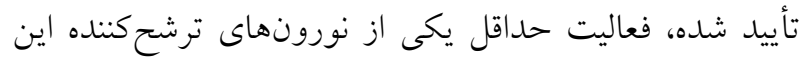
ناشى از استرس شناى اجبارى در موش كوزى آزمايشخاهى

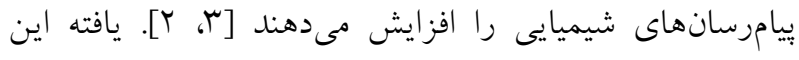

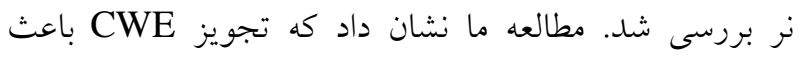
مطالعه كه تجويز عصاره آبى دارجين باعث كاهش افسردئى إنى

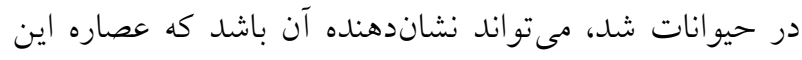

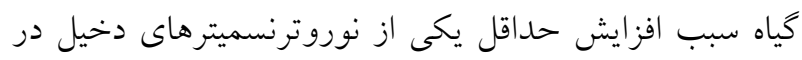

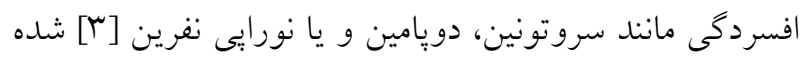

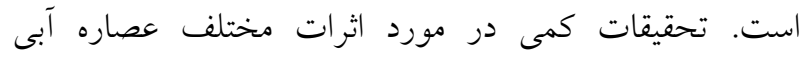

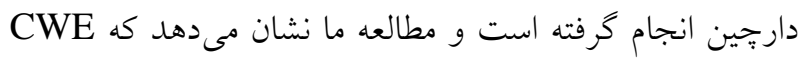

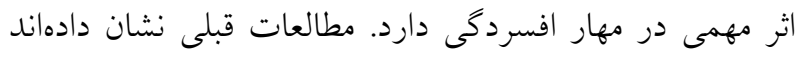

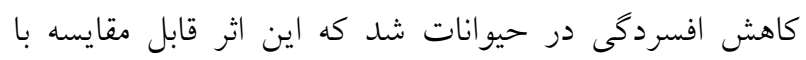

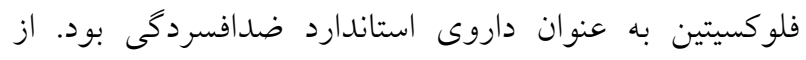

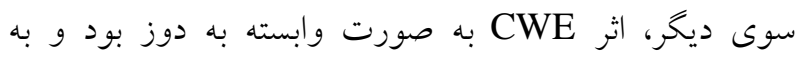

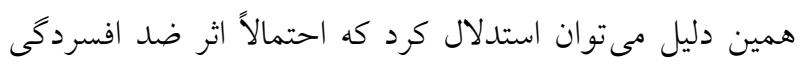

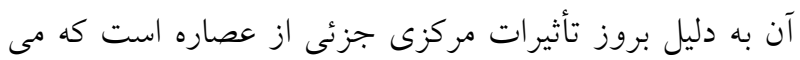

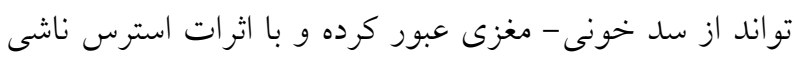
از شناى اجبارى مقابله نمايد. 
قادر به عبور از سد خونى - مغزى بوده و اثراتى را بر بخشهاى

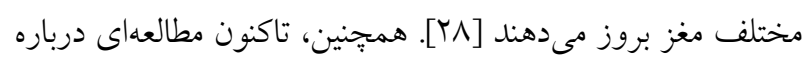

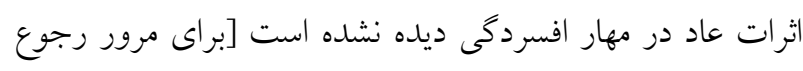

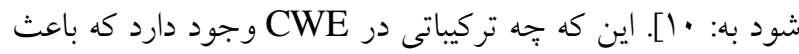

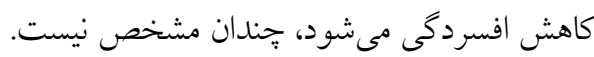

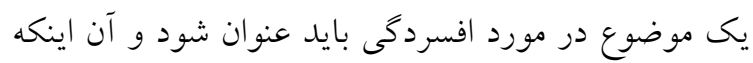

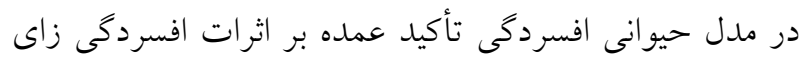

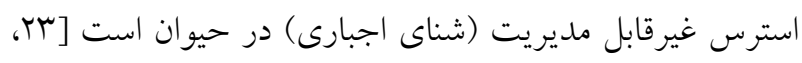

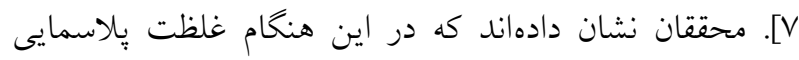

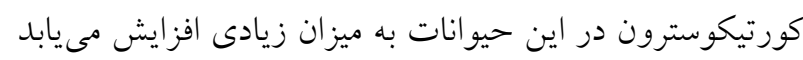

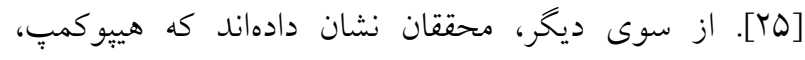

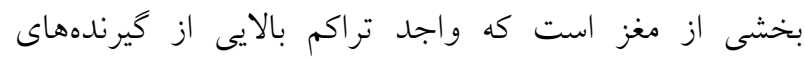

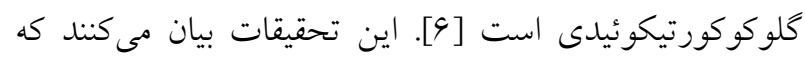

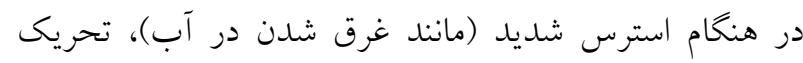

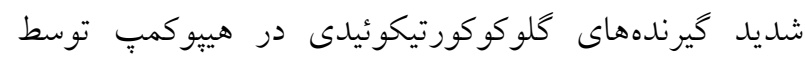

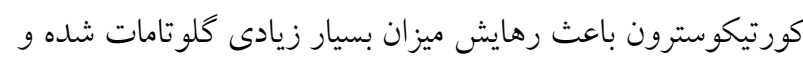

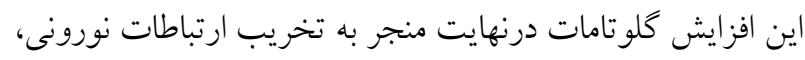

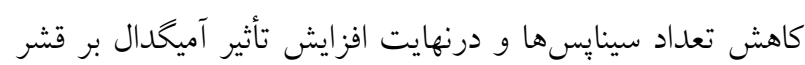

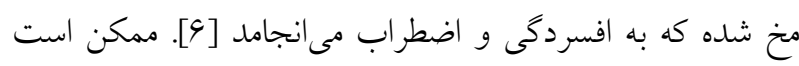
در تحقيق حاضر بخشى از اجزاء CWE با تأثير بر محور

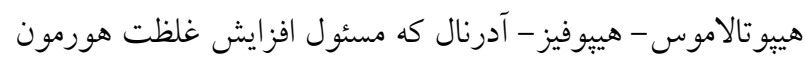

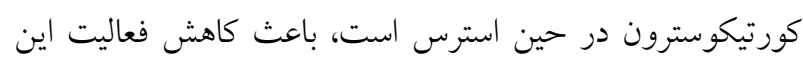

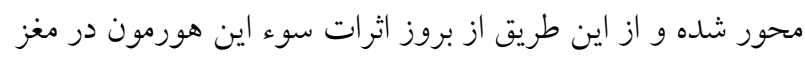
جلو گيرى كرده باشد.

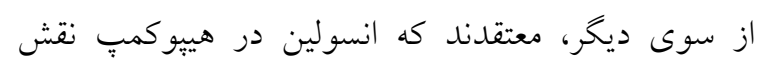

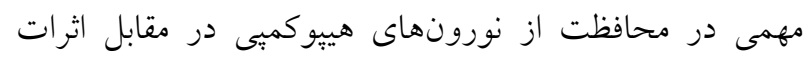

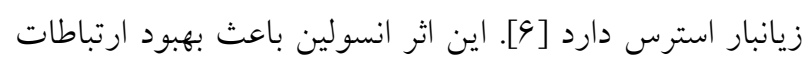

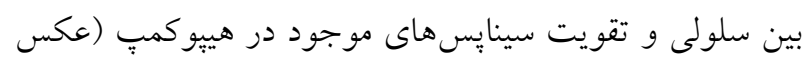

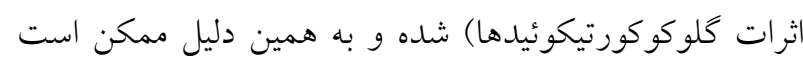

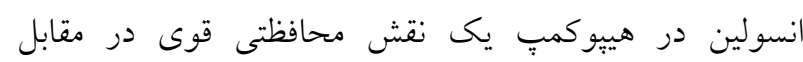

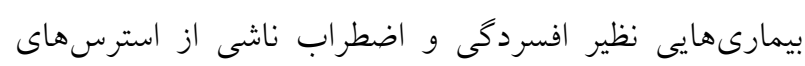

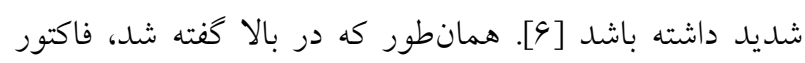

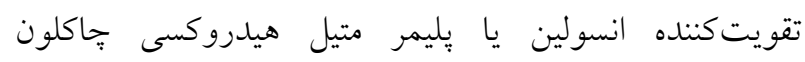
مى تواند اثرات تقويت كننده انسولين داشته و بندين (MHCP)
كه عصاره آبى - الكلى اين گياه اثربخشى خوبى در مهار فاز

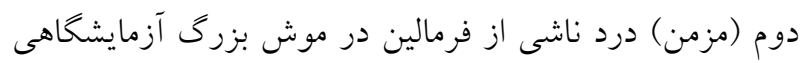

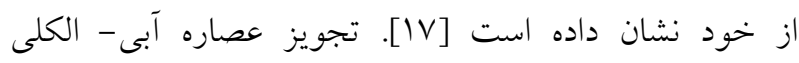

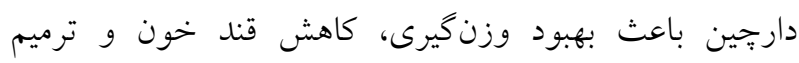

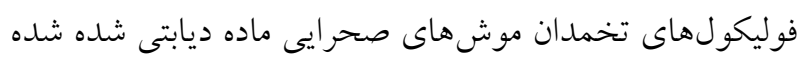

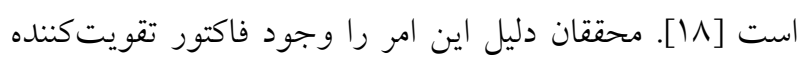

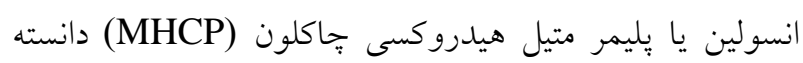

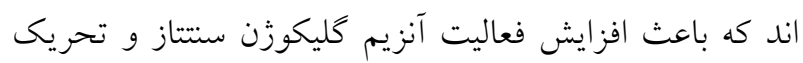

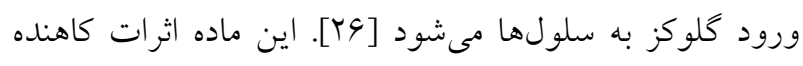

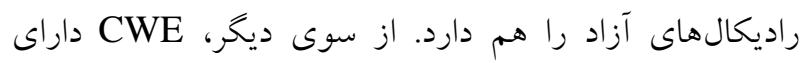

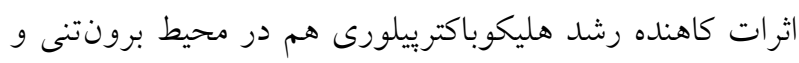

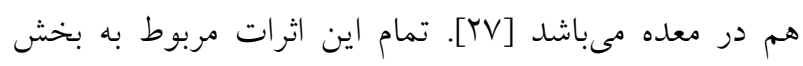

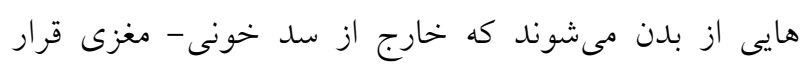

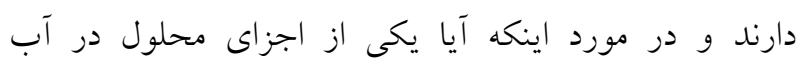

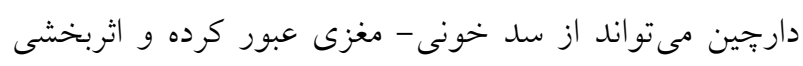

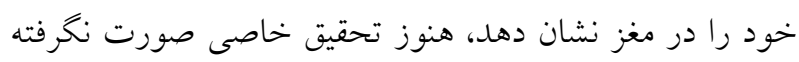
است. در حالى كه تحقيقات قبلى نشان داده است كه تركيبات

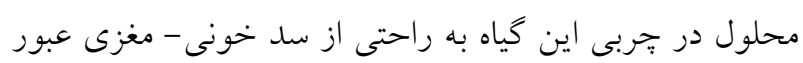

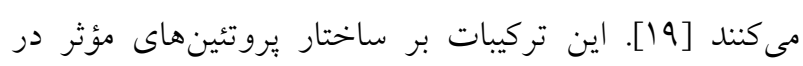

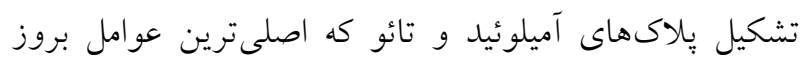

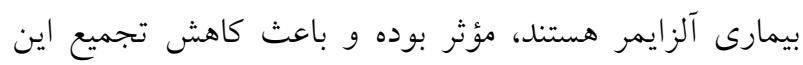

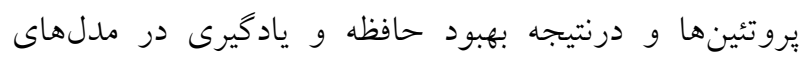

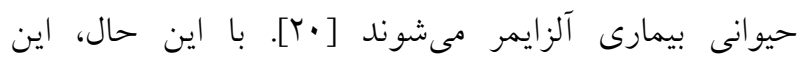

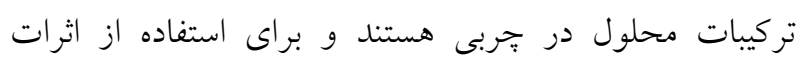

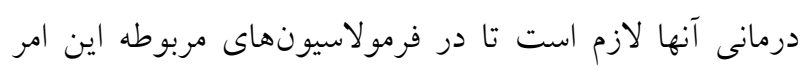

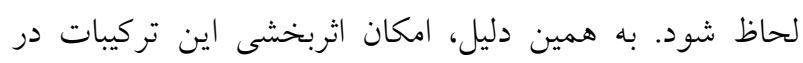

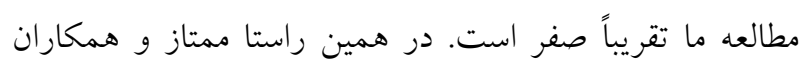

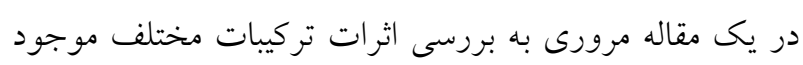

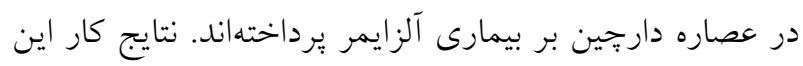

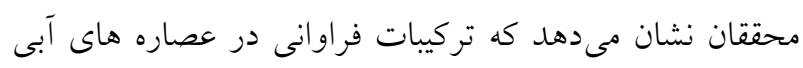

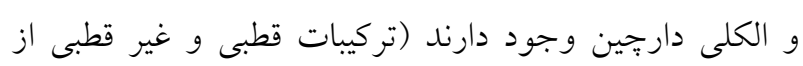

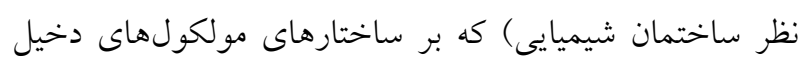

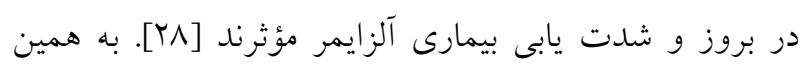

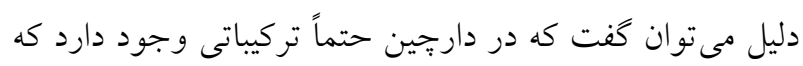


ما بيشنهاد مى كنيم كه اثرات عصاره الكلى اين گياه نيز بايستى

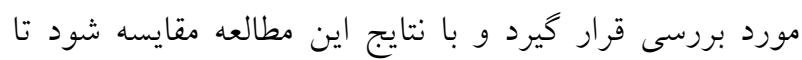

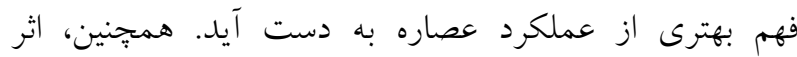

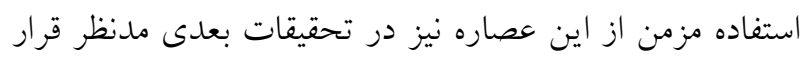

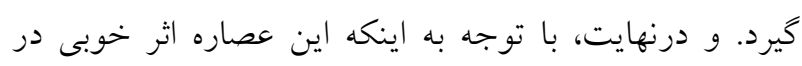

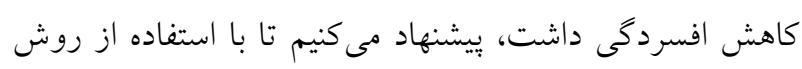

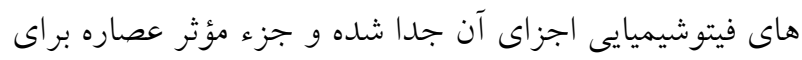

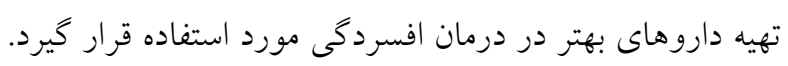

\section{تشكر و قدردانى}

اين كار با حمايت مالى مركز تحقيقات علوم اعصاب

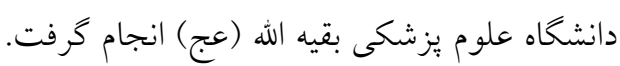
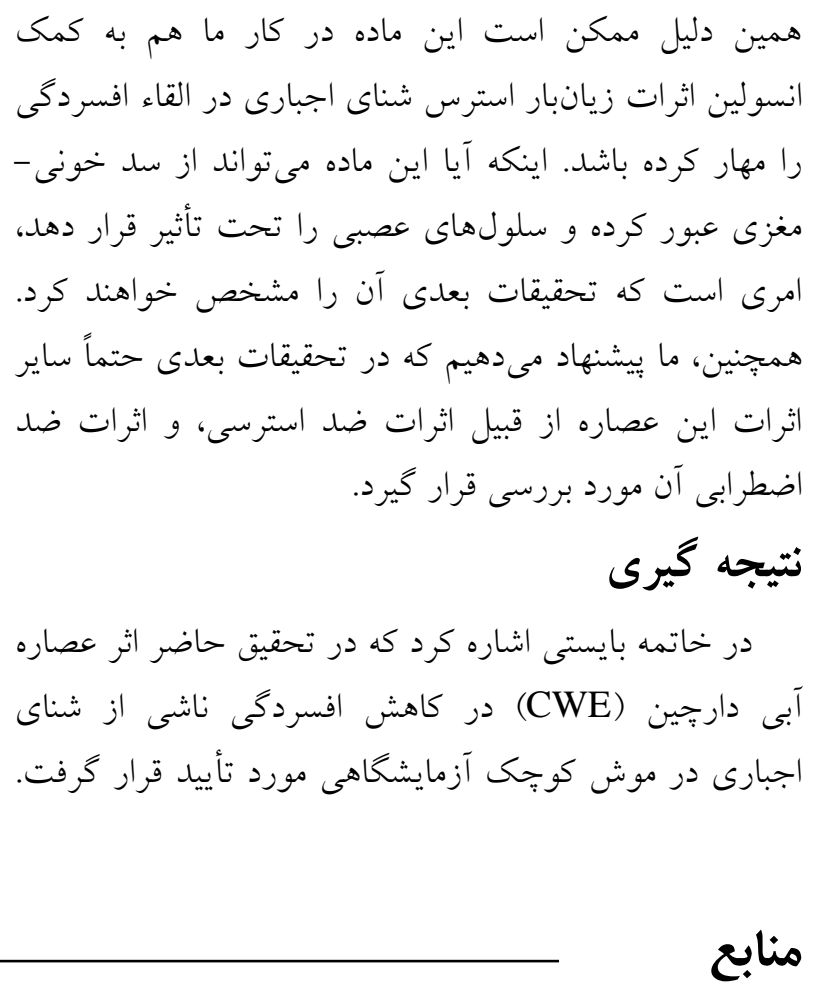

1. Nestler EJ, Barrot M, DiLeone RJ, Eisch AJ, Gold SJ and Monteggia LM. Neurobiology of depression. Neuron 2002; 34: 13 - 25.

2. Berton $\mathrm{O}$ and Nestler EJ. New approaches to antidepressant drug discovery: beyond monoamines. Nat. Rev. Neurosci. 2006; 7: 137151.

3. Blier P and de Montigny C. Current advances and trends in the treatment of depression. Trends in Pharmacological Sciences 194; 15: 220-6.

4. MacDonald TM. Treatment of depression: prescription for success? Prim. Care Psychiatry 1997; 3: 7-10.

5. Mann JJ. The medical management of depression. N. Engl. J. Med. 2005; 353: 1819-34.

6. McEwen BS. Neurobiological and systemic effects of chronic stress. Chronic Stress. 2017 Mar; 1:2470547017692328.

7. Pariante CM and Lightman SL. The HPA axis in major depression: Classical theories and new developmemts. Trends Neuroscience. 2008; 31: 464-468.
8. Drugan RC, Morrow AL, Weizman R, Weizman A, Deutsch SI and Crawley JN. Stressinduced behavioral depression in the rat is associated with a decrease in GABA receptormediated chloride ion flux and brain benzodiazepine receptor occupancy. Brain Res. 1989; 487: 45 - 51.

9. Southwick SM, Vythilingham M and Charney DS. The psychobiology of depression and resilience to stress: implications for prevention and treatment. Annu. Rev. Clin. Psychol. 2005; 1: 25591.

10. Sarris J. Herbal medicines in the treatment of psychiatric disorders: A systematic review. Phytother. Res. 2007; 21: 703-16.

11. Rao PV and Gan SH. Cinnamon: a multifaceted medicinal plant. Evid-Bas. Complem. Alternat. Med. 2014; 1-12.

12. Sohrabi M, Alahgholi-Hajibehzad M, Gholami MZ, Hosseini SS and Zamani A. Effect of cinnamon and turmeric aqueous extracts on serum interleukin-17F level of high fructose-fed rats. Iranian Journal of Immunol. 2018; 15 (1): 38-46. 
اثر ضدافسردگى عصاره ...

13. Shen $Y$, Jia LN, Honma N, Hosono T, Ariga T and Seki T. Beneficial effects of cinnamon on the metabolic syndrome, inflammation, and pain, and mechanisms underlying these effects - a review. $J$. Tradit. Complement Med. 2012; 2: 27-32.

14. Ghiasvand R, Mashhadi NS, Askari G, Feizi A, Darvishi $L$ and Hariri M. Influence of ginger and cinnamon intake on inflammation and muscle soreness endured by exercise in Iranian female athletes. Ann. Nutr. Metab. 2013; 63: 768-768.

15. Gruenwald J, Freder $\mathrm{J}$ and Armbruester N. Cinnamon and health. Critic. Rev. Food Sci. Nut. 2010; 50 (9): 822-34.

16. Shen Y, Honma N, Kobayashi K, Jia LN, Hosono $\mathrm{T}$, Shindo $\mathrm{K}$, Ariga $\mathrm{T}$ and Seki $\mathrm{T}$. Cinnamon extract enhances glucose uptake in 3T3$\mathrm{L} 1$ adipocytes and $\mathrm{C} 2 \mathrm{C} 12$ myocytes by inducing LKB1-AMP-activated protein kinase signaling. PLoS One 2014; 9 (2): e87894.

17. Dashti-Rahmatabadi M, Vahidi Merjardi A, Pilavaran A and Farzan F. Antinociceptive effect of cinnamon extract on formalin induced pain in rat. JSSU. 2009; 17 (2): 190-9.

18. Abnosi MH, Mahmoodi M, Anvari M, Dezfolian AR and Davoodzadeh H. A Study on the Effect of Cinnamon on the Structure of the Ovary in Diabetic Rats. Journal of Kerman University of Medical Sciences 2009; 16 (3): 233-43.

19. Modi KK, Rangasamy SB, Dasarathi D, Roy A, Pahan K. Cinnamon converts poor learning mice to good learners: implications for memory improvement. J. Neuroimmune Pharmacol. 2016; 11: 693-707.

20. Frydman-Marom A, Levin A, Farfara D, Benromano T, Scherzer-Attali R, Peled S, Vassar R, Segal D, Gazit E, Frenkel E. Orally administrated cinnamon extract reduces amyloid oligomerization and corrects cognitive impairment in Alzheimer's disease animal models. PLoS One. 2011; 6: e16564.

21. George RC, Lew $J$ and Graves DJ. Interaction of cinnamaldehyde and epicatechin with tau: implications of beneficial effects in modulating Alzheimer's disease pathogenesis. J. Alzheimers Dis. 2013; 6: 21 - 40.

22. Krishnan V and Nestler EJ. Animal models of depression: molecular perspectives. Curr. Top. Behav. Neurosci. 2011; 7: 121 - 47.

23. Lucki I. The forced swimming test as a model for core and component behavioral effects of antidepressant drugs. Behavioural Pharmacol. 1997; 8: 523.

24. Porsolt RD, LePichon $M$ and Jalfre $M$. Depression: a new animal model sensitive to antidepressant treatments. Nature 1977; 266: 730 -2.

25. Osanloo N, Najafi-Abedi A, Jafari F, Javid F, Pirpiran M, Jafari MR, Khosravi SA, Behzadi MR, Ranjbaran M and Sahraei H. Papaver Rhoeas L. Hydroalcoholic Extract Exacerbates Forced Swimming Test-Induced Depression in Mice. Basic Clinical Neuroscience 2016; 7 (3): 195-202. 26. Imparl-Radosevich J, Deas S, Polansky MM, Baedke DA, Ingebritsen TS, Anderson RA and Graves DJ. Regulation of PTP-1 and insulin receptor kinase by fractions from cinnamon: implications for cinnamon regulation of insulin signaling. Hormone Research in Paediatrics 1998; 50 (3): 177-82.

27. Amr RA and Maysa EM. Antiulcer effect of cinnamon and chamomile aqueous extracts in rats models. J. Am. Sci. 2010; 6: 209-16.

28. Momtaz S, Hassani S, Khan F, Ziaee $M$ and Abdollahi M. Cinnamon; a promising prospect towards Alzheimer's disease. Pharmacological Res. 2018; 130: 241-258.

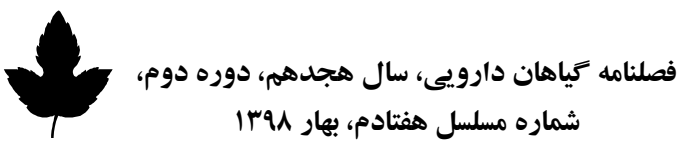




\title{
Antidepressant Effect of Cinnamon (Cinnamomum zeylanicum L.) Water Extract (CWE) Evaluated by Forced Swimming Test in Mice
}

\author{
Farahbakhsh Sh (M.Sc.) ${ }^{1}$, Hatef B (Ph.D.) ${ }^{1}$, Akhtari Z (Ph.D.) ${ }^{1}$, Bourbour Z (M.Sc.) ${ }^{1}$, Sahraei H \\ $(\text { Ph.D. })^{1^{*}}$
}

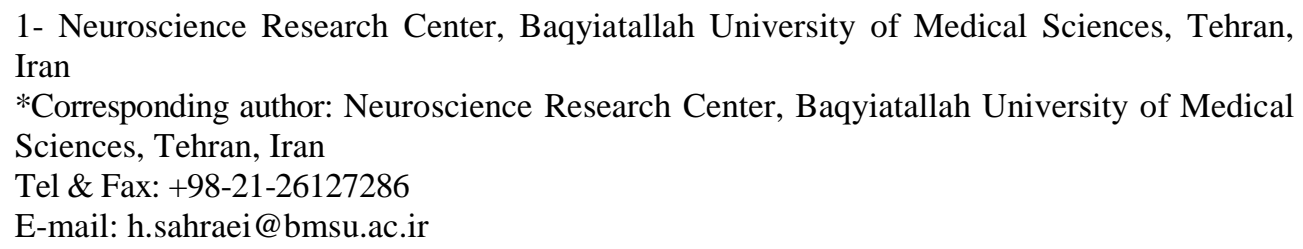

\section{Abstract}

Background: Few studies have been done considering the effectiveness of aqueous extract of cinnamon in neurological diseases. In previous studies, reducing the pain of hydro-alcoholic cinnamon extract in the second phase (chronic) of the formalin test and reduction of inflammation in animal models as well as in humans following cinnamon administration have been emphasized. There are also studies on the anti-Alzheimer's effects of this extract. However, the effects of CWE of this plant on the incidence of diseases associated with the nervous system, especially depression, have not been investigated.

Objective: In the present study, the effects of CWE on depression induced by forced swimming test (FST) in mice were investigated.

Methods: Cinnamon aqueous extract was obtained by boiling method of cinnamon powder. Male NMRI mice (25-30 g) were used (n=8/group). Different doses of CWE $(25,50,100$, and $200 \mathrm{mg} / \mathrm{kg})$ were administered intraperitoneally to the animals $30 \mathrm{~min}$ before the (FST). In addition, fluoxetine $(20 \mathrm{mg} / \mathrm{kg})$ was administered to distinct animals as positive control.

Results: Intraperitoneal $(50,100$, and $200 \mathrm{mg} / \mathrm{kg})$ injections of CWE significantly reduced the animals' immobilization in a dose-dependent manner which in doses of 100 and $200 \mathrm{mg} / \mathrm{kg}$ was similar to fluoxetine effect.

Conclusion: It could be concluded that the CWE can inhibit depression induced by FST in mice. Since the exact composition of the extract is not identified, the exact mechanism(s) by which the extract reduces the FST is not clear.

Keywords: Cinnamon Water Extract (CWE), Depression, Forced Swimming Test 